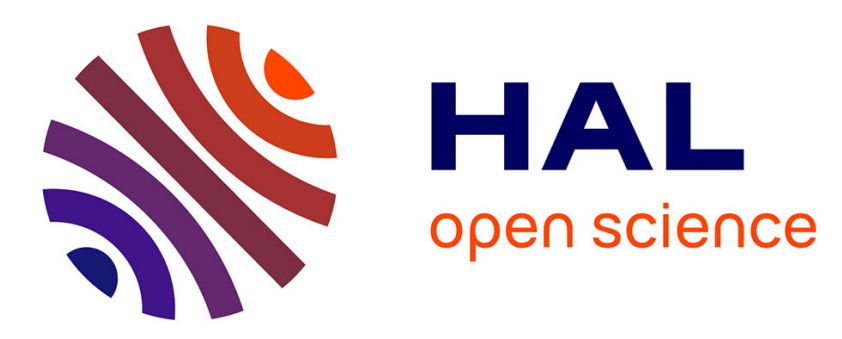

\title{
Copper-Catalyzed Aza-Iminosydnone-Alkyne Cycloaddition Reaction Discovered by Screening
}

Elodie Decuypere, Sabrina Bernard, Minghao Feng, Karine Porte, Margaux Riomet, Pierre Thuéry, Davide Audisio, Frédéric Taran

\section{- To cite this version:}

Elodie Decuypere, Sabrina Bernard, Minghao Feng, Karine Porte, Margaux Riomet, et al.. CopperCatalyzed Aza-Iminosydnone-Alkyne Cycloaddition Reaction Discovered by Screening. ACS Catalysis, 2018, 8, pp.11882-11888. 10.1021/acscatal.8b03492 . cea-01944398

HAL Id: cea-01944398 https://hal-cea.archives-ouvertes.fr/cea-01944398

Submitted on 7 Dec 2018

HAL is a multi-disciplinary open access archive for the deposit and dissemination of scientific research documents, whether they are published or not. The documents may come from teaching and research institutions in France or abroad, or from public or private research centers.
L'archive ouverte pluridisciplinaire HAL, est destinée au dépôt et à la diffusion de documents scientifiques de niveau recherche, publiés ou non, émanant des établissements d'enseignement et de recherche français ou étrangers, des laboratoires publics ou privés. 


\title{
Copper-Catalyzed Aza-Iminosydnone-Alkyne
}

\section{Cycloaddition Reaction Discovered by Screening}

\author{
Elodie Decuypere, ${ }^{[a]} *$ Sabrina Bernard,,${ }^{[a]}$ Minghao Feng, ${ }^{[a]}$ Karine Porte, ${ }^{[a]}$ Margaux \\ Riomet, ${ }^{[a]}$ Pierre Thuéry, ${ }^{[b]}$ Davide Audisio, ${ }^{[a]}$ and Frédéric Taran ${ }^{[a], *}$
}

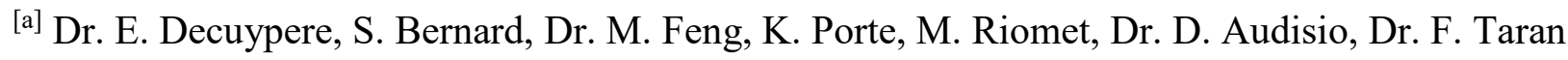
Service de Chimie Bio-organique et Marquage (SCBM), CEA/DRF/JOLIOT, Université ParisSaclay, F-91191, Gif-sur-Yvette, France

${ }^{[b]}$ Dr. P. Thuéry. NIMBE, CEA, CNRS, Université Paris-Saclay, 91191 Gif-sur-Yvette (France).

ABSTRACT The chemistry and reactivity of mesoionic compounds represent a chemical space largely unexploited. Using a MS-based screening approach, the reactivity of mesoionics toward terminal alkynes under copper catalysis has been explored. This approach led to the discovery of new reactions allowing chemoselective ligation of the two reaction partners and, simultaneously, the release of a fragment molecule. The reactivity of aza-iminosydnones allowing the selective formation of 1,2,3 triazoles or hydrazineylidene-propanal derivatives from alkynes was revealed. This copper-catalyzed reaction was found to be under the control of copper-ligand and alkyne structures. Scope of the reactions and mechanistic investigations are presented.

KEYWORDS Mesoionics, Screening, Triazoles, Cycloaddition, Copper 
Mesoionics are an old, intriguing class of dipoles often considered as exotic structures, even within the heterocyclic community. As a consequence, their chemistry and reactivity have been only sporadically explored; a rapid survey of literature indicates that less than $5 \%$ of the possible mesoionic structures have been described $\left[{ }^{[1]}\right.$ These compounds were originally defined as dipolar five-membered heterocycles with multiple aromatic resonances that cannot be satisfactorily represented without charge separation. Pioneering investigations into this class of compounds began in the early $1930 \mathrm{~s}^{[2]}$ and were significantly furthered by Huisgen in the 1960 s who worked extensively on sydnones and münchnones. ${ }^{[3]}$ These two mesoionics are still the most described in the literature and have been essentially used as dipoles in non-catalyzed, thermal cycloaddition reactions. ${ }^{[4]}$

Recently, we reported that copper salts are able to catalyze the 1,3-dipolar cycloaddition of sydnones with terminal alkynes leading to 1,4-pyrazoles under mild conditions and with complete control over regioselectivity. ${ }^{[5]}$ The reaction involves the copper-controlled [3+2] cycloaddition followed by a retro-Diels Alder (rDA) step leading to pyrazole with the concomitant extrusion of $\mathrm{CO}_{2}$ (Figure 1). Given that the reactivity of mesoionic compounds is still largely unexplored, we questioned whether other mesoionics would react under copper catalysis in presence of terminal alkynes. In this contribution, we designed and used a MS-screening approach to explore the capability of a library of selected mesoionics to undergo the $[3+2] / \mathrm{rDA}$ sequence with terminal alkynes under copper-catalysis. The screening allowed the identification of the unprecedented ligand dependent reactivity of aza-iminosydnones to access N-2-aryl-1,2,3-triazoles and hydrazineylidene-propanal derivatives. 
a) Cu-catalyzed Sydnone-Alkyne Cycloaddition (Ref 5)

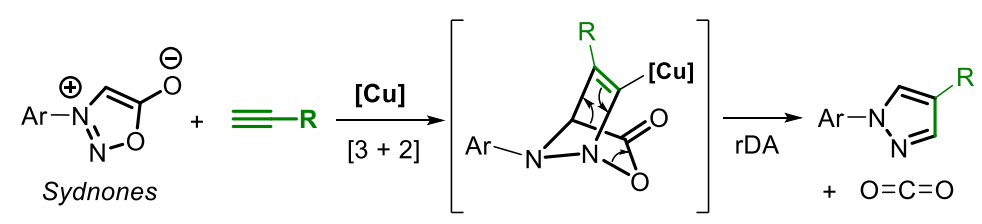

b) This work
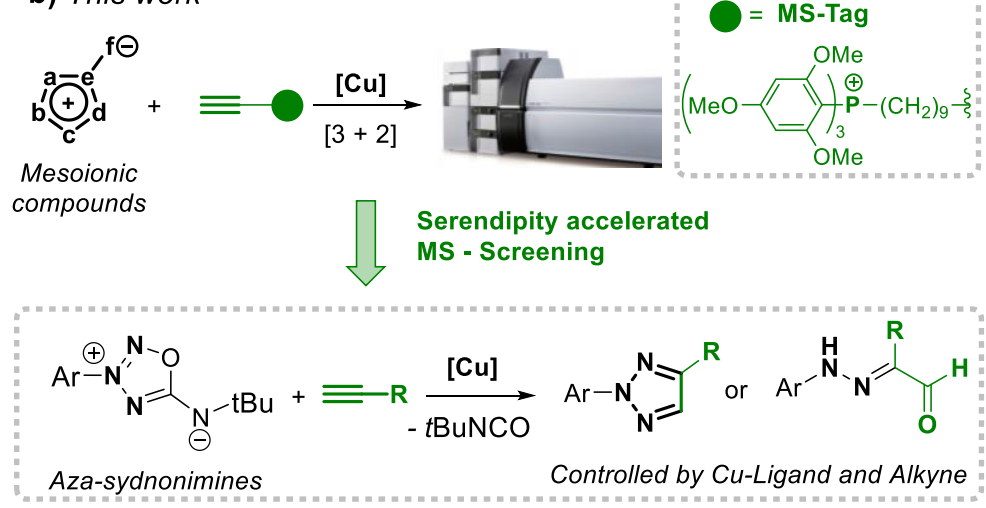

Figure 1. Cu-catalyzed alkyne-mesoionic reactions, a) Cu-catalyzed sydnone-alkyne reaction; b) Target reactions.

The screening method consists in attaching a MS-tag to the alkyne molecule to allow rapid and specific detection of tagged molecules by ESI-MS. ${ }^{[6]}$ After reaction in the presence of mesoionics and copper catalysts, the MS-tagged products can be directly detected without work-up (Figure 1b). The core experiment was conducted with a series of 24 designed mesoionics 1-24 (Figure 2b) which were mixed with the tris(2,4,6,-trimethoxyphenyl)-phosphonium TMPP-tagged terminal alkyne. Most of these mesoionics are known to undergo thermal cycloaddition with alkynes at elevated temperatures. ${ }^{[1 \mathrm{a}]}$ Each combination was then exposed to one set of reaction conditions in presence of a copper complex obtained after addition of $\mathrm{CuSO}_{4}$, sodium ascorbate and one of the nine selected ligands A-I. The corresponding 216 reactions were run overnight at room temperature and screened in few hours by direct MS analysis of the crude reactions. The results, 
indicated in Figure 2d, confirmed the reactivity of $N$-phenyl-sydnones $\mathbf{2}$ and $\mathbf{3}$ but also revealed new mesoionics $4,8,11,13,18$ and 19 , which were able to react with terminal alkynes in the presence of copper salts. However, only two, the iminosydnone 4 and the aza-iminosydnone 13 afforded reasonable yields under the tested conditions and were therefore the subject of our attention. Both reactions were reproduced in flask, on mmol scale with phenylbutyne as model alkyne, to isolate and identify the products.

Reaction of $\mathbf{4}$ with one equivalent of phenylbutyne, copper and ligand $\mathbf{B}$ gave two products, a pyrazole together with an urea product, in low yields at room temperature and moderate yields upon heating at $60^{\circ} \mathrm{C}$ (Scheme 1a). Attempts to improve the reaction efficiency were unsuccessful.

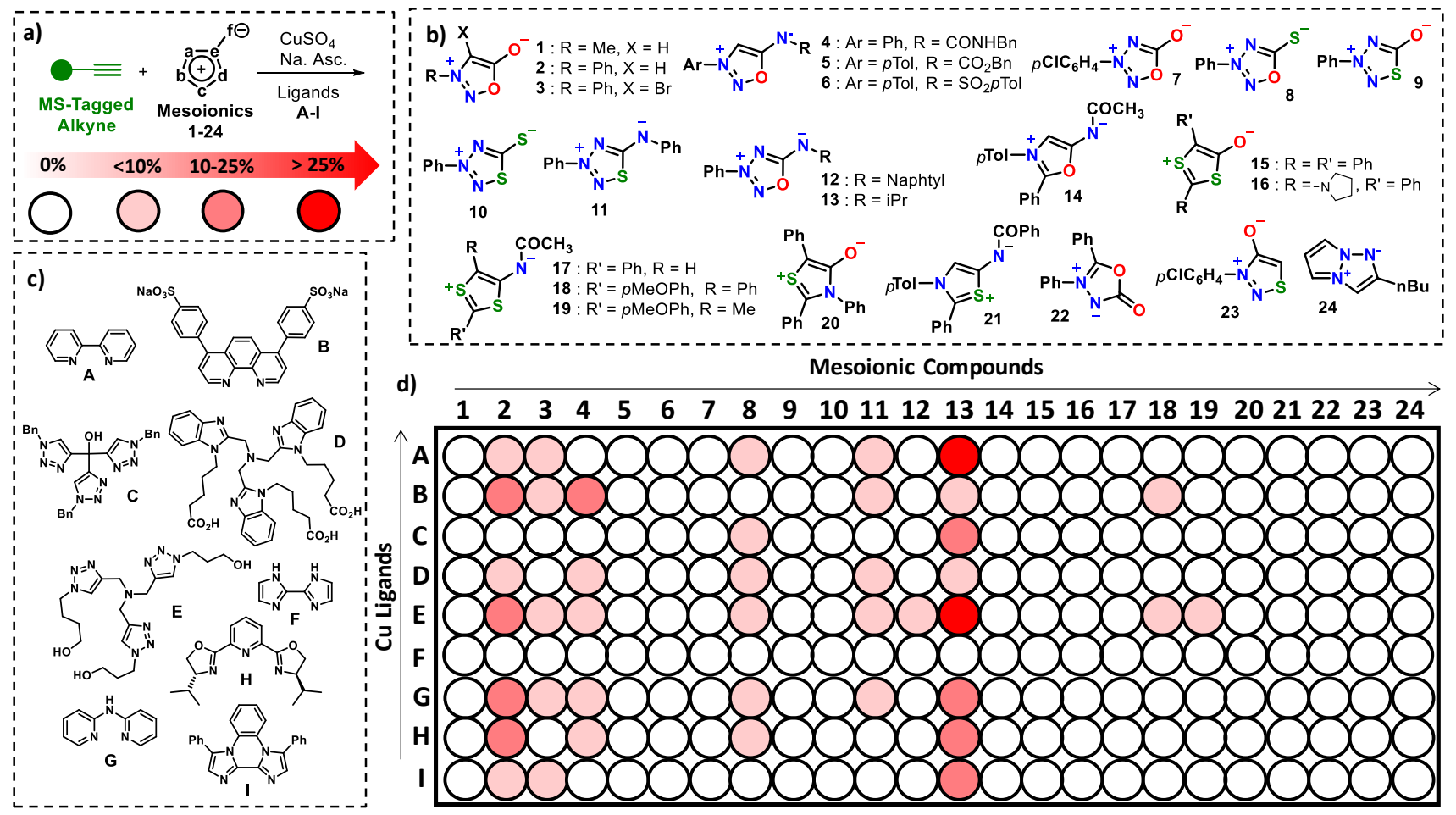

Figure 2. Parallel reactions were carried out at $25{ }^{\circ} \mathrm{C}$ in $40 \mu \mathrm{L}$ total volume of DMSO : $\mathrm{H}_{2} \mathrm{O}(60$ : 40); $[$ mesoionic $]=8 \mathrm{mM}$, $[$ TMPP-alkyne $]=7 \mathrm{mM},\left[\mathrm{CuSO}_{4}\right]$ and $[$ Ligand $]=7.25 \mathrm{mM}$, $[$ Triethanolamine $]=10 \mathrm{mM},[\mathrm{Na}$. Asc. $]=20 \mathrm{mM}$. After overnight reaction, samples were directly 
injected for MS analysis. Relative yields were determined by comparing the MS signal between the starting TMPP-tagged alkyne and the newly formed TMPP-tagged product. a) Reaction under investigation and color code. b) Structures of the mesoionic compounds used in this study. c) Structures of $\mathrm{Cu}$ ligands. d) Screening results

More interestingly, aza-iminosydnone $\mathbf{1 3}$ underwent smooth reaction at room temperature when mixed with the model alkyne in the presence of copper and ligands $\mathbf{A}$ or $\mathbf{E}$ according to the screening results. Surprisingly, although the use of ligand A afforded triazole C2 in a clean reaction, ligand $\mathbf{E}$ favored the formation of 2-(arylhydrazineylidene)propanal $\mathbf{C} \mathbf{3}$ as side product (Scheme 1b). In both cases, $i$ Pr-isocyanate $\mathbf{R} 2$ was formed as released product. To our delight, we found that the reaction was still efficient with only catalytic amounts of copper at room temperature (for optimization studies see Tables S1 and S2); attempts to improve the catalytic system by MSscreening of a library of 11 metals (including $\mathrm{Au}, \mathrm{Ag}, \mathrm{Ru}, \mathrm{Zn}$ and Ni salts) and 29 ligands (used with 1:1 and 1:5 ratios compared to metal) were unsuccessful (Figures S9 and S10). We next investigated the influence of substrate structures and found that the reaction is highly dependent on the structure of both the mesoionic and the alkyne substrate. (Table 1). 

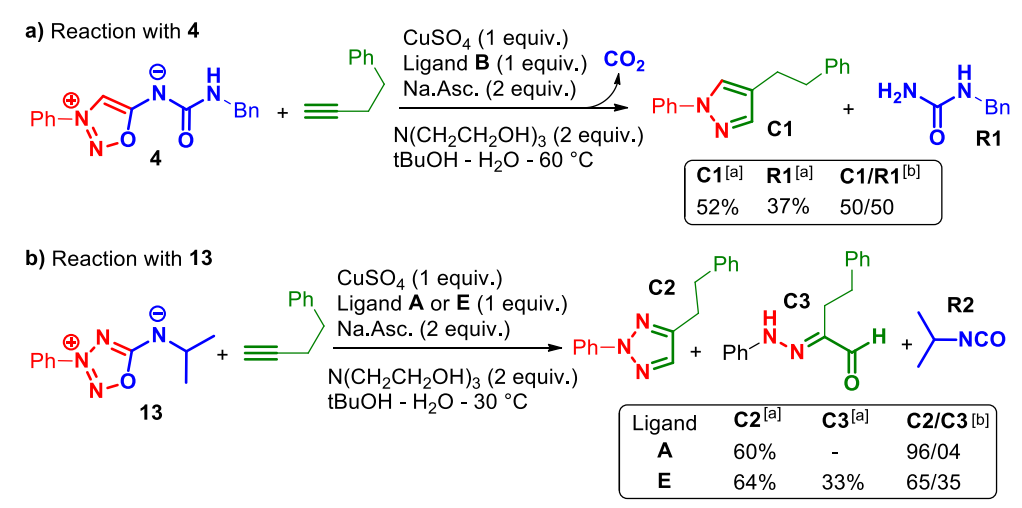

Scheme 1. Interesting reactions revealed by MS-screening. [a] isolated yields, [b] ratio determined by NMR of the crude reaction mixture.

Table 1. Influence of $\mathrm{Cu}$-ligands and substrates on the reaction ${ }^{\text {[a] }}$

\begin{tabular}{|c|c|c|c|c|c|}
\hline $\mathrm{Ph}^{-} \stackrel{\substack{N^{N} \\
N}}{\mathbf{N}}$ & $-\stackrel{N^{R}}{N^{R}}+\equiv$ & $\begin{array}{l}\mathrm{CuSO}_{4}-\mathrm{L} \\
\mathrm{N}\left(\mathrm{CH}_{2}-\mathrm{Cl}\right. \\
\mathbf{R}^{\prime} \frac{\mathrm{Na} \mathrm{Asc} .}{t \mathrm{BuOH}^{\prime} / \mathrm{H}_{2}}\end{array}$ & $\underbrace{\mathrm{nd}}_{30{ }^{\circ} \mathrm{C}}$ & $\begin{array}{l}N_{1} \\
N^{\prime}-N^{\prime} \\
C 2\end{array}$ & $\mathrm{~N}_{\mathrm{N}}^{\mathrm{H}}{ }_{\mathrm{C}}^{\mathrm{R}}$ \\
\hline Entry & $R$ & $\mathrm{R}^{\prime}$ & Ligand & Yield ${ }^{[b]}$ & $\mathrm{C2}: \mathrm{C}^{\left[{ }^{[c]}\right]}$ \\
\hline 1 & $n \mathrm{Pr}$ & $-\left(\mathrm{CH}_{2}\right)_{2} \mathrm{Ph}$ & A & traces & - \\
\hline 2 & $\mathrm{iPr}$ & $-\left(\mathrm{CH}_{2}\right)_{2} \mathrm{Ph}$ & A & $32 \%$ & $>98: 02$ \\
\hline 3 & $t \mathrm{Bu}$ & $-\left(\mathrm{CH}_{2}\right)_{2} \mathrm{Ph}$ & A & $78 \%$ & $>98: 02$ \\
\hline 5 & $\mathrm{Ph}$ & $-\left(\mathrm{CH}_{2}\right)_{2} \mathrm{Ph}$ & A & traces & - \\
\hline 6 & $\mathrm{COPh}$ & $-\left(\mathrm{CH}_{2}\right)_{2} \mathrm{Ph}$ & A & no reaction & - \\
\hline 7 & $t \mathrm{Bu}$ & $-\mathrm{CH}_{2} \mathrm{OH}$ & A & $29 \%$ & $44: 66$ \\
\hline 8 & tBu & $-\left(\mathrm{CH}_{2}\right)_{2} \mathrm{OH}$ & A & $70 \%$ & $95: 05$ \\
\hline 9 & $t \mathrm{Bu}$ & $-\left(\mathrm{CH}_{2}\right)_{4} \mathrm{OH}$ & A & $69 \%$ & $94: 06$ \\
\hline 10 & $t \mathrm{Bu}$ & $-\left(\mathrm{CH}_{2}\right)_{2} \mathrm{Ph}$ & E & $34 \%$ & $49: 51$ \\
\hline 11 & $t \mathrm{Bu}$ & $-\mathrm{CH}_{2} \mathrm{OH}$ & E & $78 \%$ & $17: 83$ \\
\hline 12 & tBu & $-\left(\mathrm{CH}_{2}\right)_{4} \mathrm{OH}$ & E & $75 \%$ & $60: 40$ \\
\hline
\end{tabular}

[a] Experiments were carried out overnight at $0.1 \mathrm{M}$ with 0.2 equiv. of copper and ligand, 1.5 equiv. mesoionic, 1 equiv. of triethanolamine and Na. Asc. [b] Global $(\mathrm{C} 2+\mathrm{C} 3)$ isolated yields. [c] $\mathrm{C} 2 / \mathrm{C} 3$ ratios were determined by NMR on crude reaction mixture. 
Bulky tert-butyl substitution on the hexocyclic nitrogen atom of the mesoionic was found particularly important for the efficiency of the process and no reaction took place when an aryl or a benzoyl is linked at this position (entries 1-6 in Table 1). Alkynes bearing a heteroatom in propargylic position and the use of ligand $\mathbf{E}$ favoured the formation of product $\mathbf{C} \mathbf{3}$ (compare entries 7-9 and 10-12 in Table 1) whereas regular alkynes and ligand $\mathbf{A}$ favoured the formation of triazoles C2 in good yields and selectivity. With this information in our hands, we looked at the scope of the reactions under the optimized conditions. As illustrated in Scheme 2, the reactions showed good function tolerances and the desired triazoles or hydrazono-aldehydes products were obtained as the major products when using the proper copper ligand. 


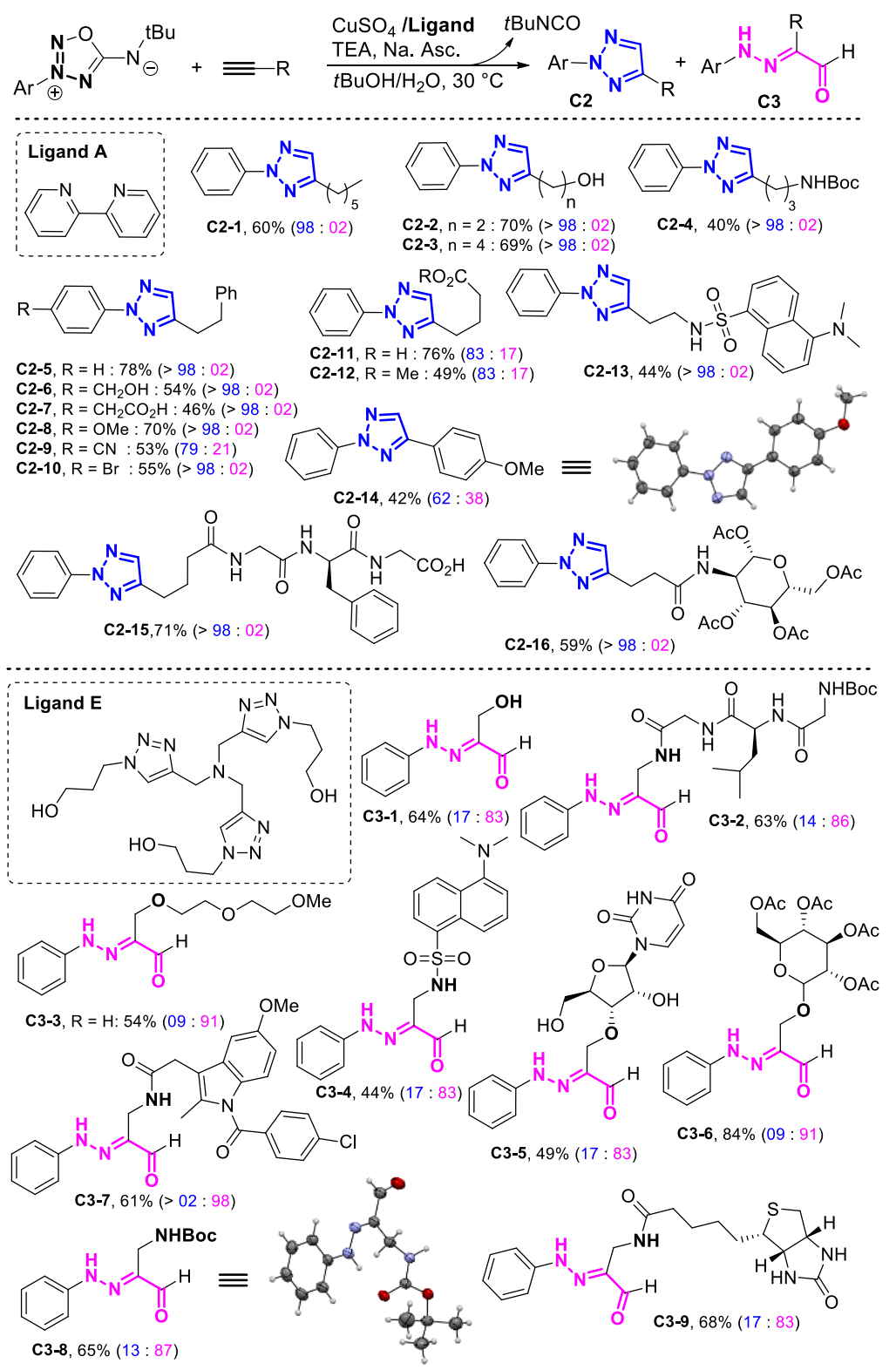

Scheme 2. Scope of the reactions. Reactions were carried out at $0.1 \mathrm{M}$ with 0.2 equiv. of copper and ligand, 1.5 equiv. of mesoionic, 1 equiv. of triethanolamine (TEA) and 1 equiv. of sodium ascorbate (Na. Asc.). \% values correspond to isolated yields of the major product. C2/C3 ratios were determined by NMR on the crude reaction mixtures. 
In general, the use of ligand $\mathbf{A}$ allowed the formation of the desired triazole with excellent selectivity. The presence of substituents on the aromatic moiety of the mesoionic did not affect reactivity. On the other hand, the presence of ligand $\mathbf{E}$ and an oxygen or nitrogen atom in propargylic position highly favored the formation of the corresponding aldehyde $\mathbf{C} 3$, suggesting a possible internal coordination with the copper center. In addition, the peculiar structures of C2-14 and C3-8 were unambiguously confirmed by X-ray crystallography. Both reactions proceeded well with multi-functionalized substrates such as sugars $(\mathbf{C 2 - 1 6}, \mathbf{C 3 - 5}$ and $\mathbf{C 3 - 6})$ and peptides $(\mathbf{C} 2-15$ and C3-2), derivatization of the nonsteroidal anti-inflammatory drug indomethacin was also effective (C3-7). However, the reactions showed also some limitations in term of alkyne substrate scope: disubstituted alkynes were found inactive and ynamides, hindered or sulfur containing alkynes were poor substrates for the reaction (Figures S11-12). With the exception of these types of alkynes, the reaction was found quite effective on a large panel of substrates. It is worth noting that the development of practical and efficient methods for both $N$-2-substitued-1,2,3-triazoles $\mathbf{C 2}{ }^{[7]}$ and aldehydes derivatives $\mathbf{C 3}^{[8]}$ received only limited attention. Compared to these known methodologies, the described reaction presents milder conditions and better functional group tolerance therefore representing an interesting alternative method to prepare these products known for their photo-physical and biological properties. ${ }^{[9]}$

Interestingly, we then found that aza-iminosydnones are not reactive toward activated or strained alkynes: no reaction took place when mixing aza-iminosydnones with the cyclooctyne bicyclo[6.1.0]-nonyne (BCN) or with dimethylacetylene dicarboxylate (DMAD) even at elevated temperatures. We therefore designed and synthesized the bifunctional compound $\mathbf{2 5}$ bearing azide and aza-iminosydnone moieties (Scheme 3). 


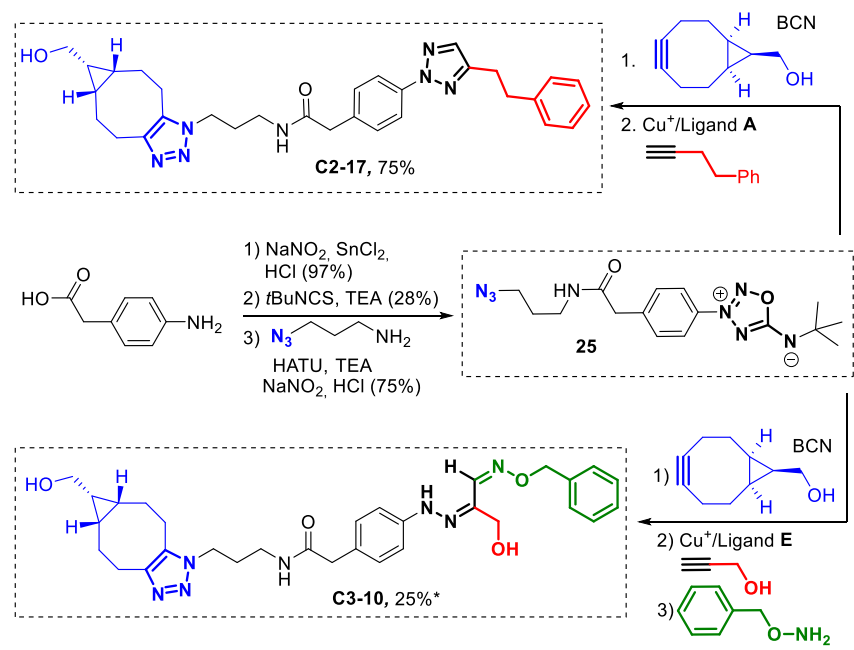

Scheme 3. Application of the reaction to double and triple ligations. *isolated yield after preparative HPLC.

Reaction of $\mathbf{2 5}$ with $\mathbf{B C N}$ was very clean and afforded quantitatively the corresponding triazole without affecting the mesoionic structure demonstrating the perfect orthogonality of the $\mathrm{Cu}$ catalyzed aza-iminosydnone/alkyne reaction towards the strained-promoted azide/alkyne cycloaddition reaction (SPAAC). ${ }^{[10]}$ After this SPAAC step, the product was successfully converted to either bis-triazole $\mathbf{C 2 - 1 7}$ using the Cu-Ligand A system or to the aldehyde product using the $\mathrm{Cu}$-Ligand $\mathbf{E}$ system which was subsequently derivatised by oxime ligation to afford $\mathbf{C 3 -}$ 10. Although the obtained yield was moderate ( $25 \%$ for 3 steps $)$, this experiment showed the possibility to use the $\mathrm{Cu}$-catalyzed azaiminosydnone/alkyne reaction for triple ligation reactions.

To investigate the mechanism of the reaction we performed a series of experiments using isotopically enriched substrates (see supporting information for their synthesis). As shown in Scheme $4 \mathrm{a}$, the use of ${ }^{15} \mathrm{~N}$-enriched aza-iminosydnones and ${ }^{13} \mathrm{C}$-enriched heptyn-1-ol proved that the copper-catalyzed reactions are completely regioselective. In all cases, only one single labeled 
product was obtained demonstrating that a $\mathrm{C}-\mathrm{N}$ bond is formed between the terminal sp-carbon of the alkyne and the nitrogen atom in position 4 of the mesoionic, the second formed $\mathrm{C}-\mathrm{N}$ bond involving the nitrogen in position 2. The results indicated also that the formation of products $\mathbf{C} \mathbf{3}$ involves a loss of nitrogen in position 4 while experiments conducted in presence of $\mathrm{D}_{2} \mathrm{O}$ or $\mathrm{H}_{2}{ }^{18} \mathrm{O}$ suggest hydrolysis of an intermediate to form products $\mathbf{C 3}$ (Scheme 4a). Based on these results and on established mechanisms involving copper(I) acetylide species, ${ }^{[11]}$ we postulated a mechanism involving coordination of the N-4 atom of the aza-iminosydnone substrate to the copper center of the acetylide enhancing the electrophilicity of the N-2 atom which ultimately results in the formation of the two C-N bonds to form the bicyclic intermediate I (Scheme 4b). This intermediate might then undergo a retro-Diels Alder reaction with extrusion of an isocyanate molecule to form intermediate II or III depending on the Cu-ligand. Intermediate II obtained with bidentate ligand $\mathbf{A}$ would then undergo simple protonation to afford product $\mathbf{C 2}$. Intermediate III obtained with tetradentate ligand $\mathbf{E}$ able to complex two $\mathrm{Cu}$ atoms would be more sensitive to reaction conditions and would decompose by ring opening of the triazole core through N-N bond breaking and subsequent hydrolysis to generate product $\mathbf{C 3}$ (Scheme $4 \mathrm{~b}$ ).
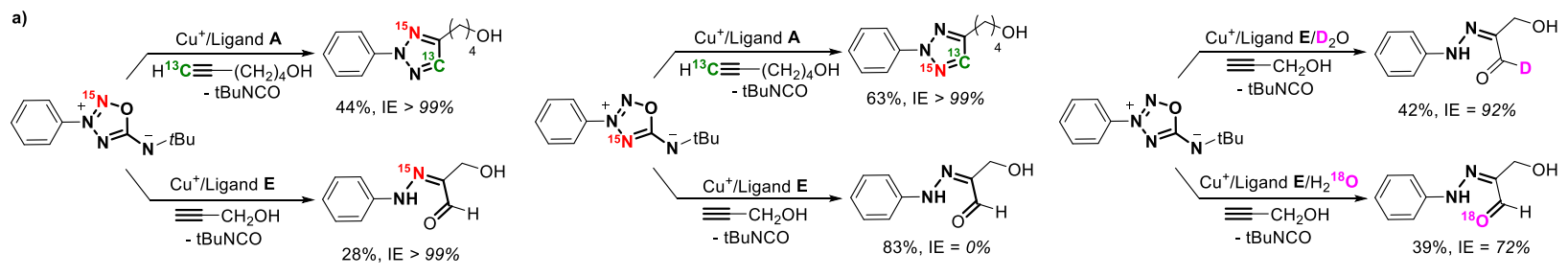

b)

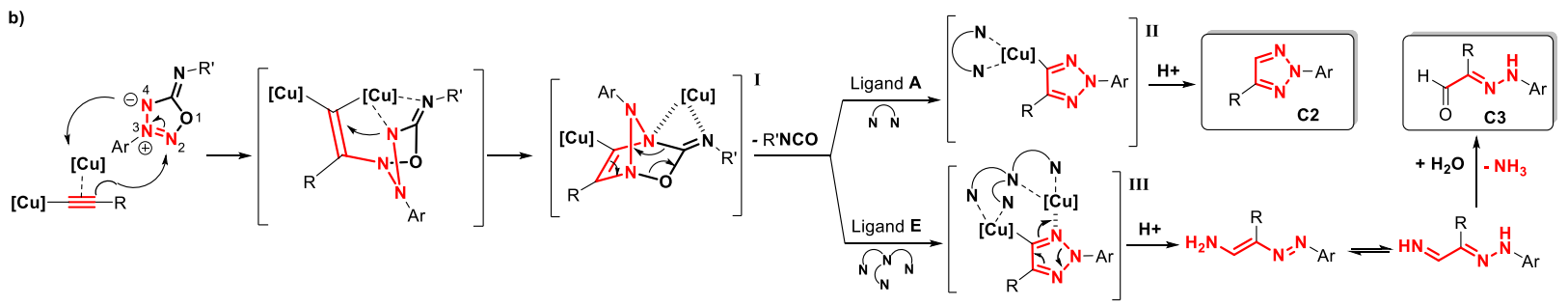


Scheme 4. Mechanistic investigations. a) Experiments with isotopically labelled substrates. Reactions were carried out at $0.1 \mathrm{M}$ with 0.2 equiv. of copper and ligand, 1 equiv. of TEA and 1 equiv. of Na. Asc.; IE = isotopic enrichment; b) Proposed mechanism for the Cu-catalyzed azaiminosydone-alkyne reactions.

In summary, we described in this paper the first example of a $\mathrm{Cu}$-catalyzed reaction allowing both ligation of two substrates and release of a fragment molecule. The reaction involves azaiminosydnones, a family of mesoionic compounds rarely described in literature, ${ }^{[12]}$ which generate 1,2,3-triazoles or 2-hydrazineylidene-propanal derivatives depending on the $\mathrm{Cu}$-ligand and the alkyne used, together with an isocyanate release product. The reaction is wide in scope, uses mild conditions and shows very good function tolerance. Besides its synthetic interest, the excellent orthogonality of the reaction with the SPAAC reaction may also find nice applications in the field of ligation reactions. Mesoionic ring systems represent a fascinating and still under-exploited collection of putative 1,3-dipoles useful for cycloaddition chemistry. This study showed how the exploration of this chemical space using high-throughput screening conducted to interesting discoveries.

\section{AUTHOR INFORMATION}

\section{Corresponding Author}

E-mail: frederic.taran@cea.fr

\section{Author Contributions}

$\$$ These authors contributed equally. 


\section{Funding Sources}

This work was supported by the French Research National Agency (ANR-14-CE06-0004).

\section{Notes}

The authors declare no competing financial interest.

\section{SUPPORTING INFORMATION}

Screening data, optimization data, additional experimental data on substrate scope, synthetic procedures and analytical data of reactants and products.

\section{ACKNOWLEDGMENT}

The authors thank Elodie Marcon and David-Alexandre Buisson for excellent analytical support and Dr. Philippe Dauban (CNRS, ICSN) for helpful discussions.

\section{REFERENCES}

[1] For reviews on mesoionics, see : a) Lopchuk, J. M. In Topics in Heterocyclic Chemistry, Gribble G. W., Eds.; Springer, 2012 ; Vol. 29, p 381. b) Avalos, M.; Babiano, R.; Cintas, P.; Jiménez, J. L.; Palacios, J. C.; Exploiting Synthetic Chemistry with Mesoionic Rings: Improvements Achieved with Thioisomünchnones. Acc. Chem. Res. 2005, 38, 460-468. c) Ollis, W. D.; Stanforth, S. P.; Ramsden, C. A.; Heterocyclic Mesomeric Betaines. Tetrahedron 1985, 41, 2239-2329. d) Ollis, W. D.; Ramsden, C. A.; Mesoionic Compounds. Adv. Heterocycl. Chem. 1976, 19, 1-122. For books on mesoionics, see: e) Padwa, A.; Peason, W. H. In Chemistry of Heterocyclic Compounds: A Series Of Monographs, Eds.; Copyright (C) John Wiley \& Sons, Inc.2003; Vol. 59. f) Sammes, P. G. In Comprehensive Organic Chemistry, $1^{\text {st }}$ ed. Barton, D.; Ollis, W. D., Eds.: D. Barton, W. D. Ollis, Pergamon, Oxford, 1979; Vol. 4 p 1171 
[2] Earl, J. C.; Mackney, A.W. The Action of Acetic Anhydride on $N$-nitrosophenylglycine and Some of its Derivatives. J. Chem. Soc. 1935, 0, 899-900.

[3] Huisgen, R.; Grashley, R.; Gotthardt, H.; Schmidt, R. 1,3-Dipolar Additions of Sydnones to Alkynes. A New Route into the Pyrazoles Series. Angew. Chem. Int. Ed. 1962, 1, 48-49.

[4] a) Reissig, H-U.; Zimmer, R. Münchnones-New Facets after 50 Years. Angew. Chem. Int. Ed. 2014, 53, 9708-9710. b) Browne, D. L.; Harrity, J. P. A. Recent Developments in the Chemistry of Sydnones. Tetrahedron. 2010, 66, 553-568. c) Gribble. G. W. In Synthetic Applications of 1,3-Dipolar Cycloaddition Chemistry Toward Heterocycles and Natural Products, Padwa, A., Pearson W. H., Eds.; Wiley, New York, 2003; p 681. d) Almendros, P.; Yanai, H.; Hoshikawa, S.; Aragoncillo, C.; Lázaro-Milla, C.; Toledano-Pinedo, M.; Matsumoto, T.; Alcaide, B. Transition Metal-Free Controlled Synthesis of Bis[(trifluoromethyl)sulfonyl]ethyl-decorated Heterocycles. Org. Chem. Front., 2018, 5, 3163-3169.

[5] a) Kolodych, S.; Rasolofonjatovo, E.; Chaumontet, M.; Nevers, M-C.; Créminon, C.; Taran, F. Discovery of Chemoselective and Biocompatible Reactions Using a High-Throughput Immunoassay Screening. .Angew. Chem. Int. Ed. 2013, 52, 12056-12060. b) Specklin, S.; Decuypere, E.; Plougastel, L.; Aliani, S.; Taran. F. One-Pot Synthesis of 1,4-Disubstituted Pyrazoles from Arylglycines via Copper-Catalyzed Sydnone-Alkyne Cycloaddition Reaction. $J$. Org. Chem. 2014, 79, 7772-7777. c) Decuypere, E.; Specklin, S.; Gabillet, S.; Audisio, D.; Liu, H.; Plougastel, L.; Kolodych, S.; Taran, F. Copper(I)-Catalyzed Cycloaddition of 4Bromosydnones and Alkynes for the Regioselective Synthesis of 1,4,5-Trisubstituted Pyrazoles. Org. Lett. 2015, 17, 362-365. d) Liu, H.; Audisio, D.; Plougastel, L.; Decuypere, E.; Buisson, DA.; Koniev, O.; Kolodych, S.; Wagner, A.; Elhabiri, M.; Krzyczmonik, A.; Forsback, S.; Solin, O.; Gouverneur, V.; Taran. F. Ultrafast Click Chemistry with Fluorosydnones. Angew. Chem. Int. Ed. 2016, 55, 12073-12077. 
[6] a) Leavens, W. J.; Lane, S. J.; Carr, R. M.; Lockie, A. M.; Waterhouse, I. Derivatization for Liquid Chromatography/Electrospray Mass Spectrometry: Synthesis of Tris(trimethoxyphenyl)phosphonium Compounds and their Derivatives of Amine and Carboxylic Acids. Rapid Commun. in Mass Spectrometry. 2002, 16, 433-441. b) Karnezis, A.; Barlow, C. K.; O'Hair, R. A. J.; McFadyen, W. D. Peptide Derivatization as a Strategy to Form Fixed-Charge Peptide Radicals. Rapid Commun. in Mass Spectrometry. 2006, 20, 2865-2870. c) Nakajima, C.; Kuyama, H.; Nakazawa, T.; Nishimura, O.; Tsunasawa, S.; A Method for N-terminal de Novo Sequencing of Na-blocked Proteins by Mass Spectrometry. Analyst. 2011, 136, 113-119. d) Koniev, O.; Leriche, G.; Nothisen, M.; Remy, J-S.; Strub, J-M.; Schaeffer-Reiss, C.; Van Dorsselaer, A.; Baati, R.; Wagner, A. Selective Irreversible Chemical Tagging of Cysteine with 3Arylpropiolonitriles. Bioconjugate Chem. 2014, 25, 202-206.

[7] a) Wang, X.; Zhang, L.; Lee, H.; Haddad, N.; Krishnamurthy, D.; Senanayake, C. H. Highly Regioselective N-2 Arylation of 4,5-Dibromo-1,2,3-triazole: Efficient Synthesis of 2Aryltriazoles. Org. Lett. 2009, 11, 5026-5028. b) Liu, Y.; Yan, W.; Chen, Y.; Petersen, J. L.; Shi, X. Efficient Synthesis of N-2-Aryl-1,2,3-Triazole Fluorophores via Post-Triazole Arylation. Org. Lett. 2008, 10, 5389-5392. c) Ueda, S.; Su, M.; Buchwald, S. L. Highly $N^{2}$-Selective PalladiumCatalyzed Arylation of 1,2,3-Triazoles. Angew. Chem. Int. Ed. 2011, 50, 8944-8947. d) Liu, Z.; Ji, H.; Gao, W.; Zhu, G.; Tong, L.; Lei, F.; Tang, B. Copper(I)-Mediated Carboamination of Vinyl Azides by Aryldiazonium Salts: Synthesis of $N^{2}$-substituted 1,2,3-Triazoles. Chem. Commun. 2017, 53, 6259-6262. e) Guru, M. M.; Punniyamurthy, T. Copper(II)-Catalyzed Aerobic Oxidative Synthesis of Substituted 1,2,3- and 1,2,4-Triazoles from Bisarylhydrazones via C-H Functionalization/C-C/N-N/C-N Bonds Formation. J. Org. Chem. 2012, 77, 5063-5073. f) Wu, L.; Guo, S.; Wang, X.; Guo, Z.; Yao, G.; Lin, Q.; Wu, M. Tandem Synthesis of 2-aryl-1,2,3- 
triazoles from $\alpha$-arylhydrazonoketones with $\mathrm{NH}_{4} \mathrm{OAc}$ via Copper-Catalyzed Aerobic Oxidation. Tetrahedron Lett. 2015, 56, 2145-2148.

[8] a) Al-Omran, F.; Khalik, M. M. A.; Abou-Elkhair, A.; Elnagdi, M. H. Studies With Functionally Substituted Heteroaromatics: A Novel Route for the Synthesis of 1-Aryl-6oxopyridazinones, 1-Arylpyridazine-6-imines and 1-Aryl-6-imino-4-pyridazinals. Synthesis 1997, 91-94. b) Al-Awadi, N. A.; Elnagdi, M. H.; Ibrahim, Y. A.; Kaul, K.; Kumar, A. Efficient Synthesis of 3-aroylcinnolines from Aryl Methyl Ketones. Tetrahedron 2001, 57, 1609-1614.

[9] a) Yan, W.; Wang, Q.; Lin, Q.; Li, M.; Petersen, J. L.; Shi, X. N-2-Aryl-1,2,3-triazoles: A Novel Class of UV/Blue-Light-Emitting Fluorophores with Tunable Optical Properties. Chem. Eur. J., 2011, 17, 5011-5018. b) Giroud, M.; Kuhn, B.; Saint-Auret, S.; Kuratli, C.; Martin, R. E.; Schuler, F.; Diederich, F.; Kaiser, M.; Brun, R.; Schirmeister. T. 2H-1,2,3-Triazole-Based Dipeptidyl Nitriles: Potent, Selective, and Trypanocidal Rhodesain Inhibitors by Structure-Based Design. J. Med. Chem. 2018, 61, 3370-3388. c) Watanabe, T.; Umezawa, Y.; Takahashi, Y.; Akamatsu, Y. Novel Pyrrole- and 1,2,3-triazole-based 2,3-oxidosqualene Cyclase Inhibitors. Bioorg. Med. Chem. Lett. 2010, 20, 5807-5810. d) Gonzaga, D.; Senger, M. R.; de Carvalho da Silva, F.; Ferreira, V. F.; Silva Jr., F. P. 1-Phenyl-1H-and 2-phenyl-2H-1,2,3-triazol Derivatives: Design, Synthesis and Inhibitory Effect on Alpha-glycosidases. Eur. J. Med. Chem. 2014, 74, 461476.

[10] For reviews on SPAAC, see: a) Sletten, E. M.; Bertozzi, C. R. From Mechanism to Mouse: A Tale of Two Bioorthogonal Reactions. Acc. Chem. Res. 2011, 44, 666-676. b) Debets, M. F.; Van Berkel, S. S.; Dommerholt, J.; Dirks, A. J.; Rutjes, F. P. J. T.; Van Delft, F. L. Bioconjugation with Strained Alkenes and Alkynes. Acc. Chem. Res. 2011, 44, 805-815. 
[11] a) Ahlquist, M.; Fokin, V. V. Enhanced Reactivity of Dinuclear Copper(I) Acetylides in Dipolar Cycloadditions. Organometallics 2007, 26, 4389-4391. b) Rodionov, V. O.; Fokin, V. V.; Finn, M. G. Mechanism of the Ligand-Free $\mathrm{Cu}^{\mathrm{I}}$-Catalyzed Azide-Alkyne Cycloaddition Reaction. Angew. Chem. Int. Ed. 2005, 44, 2210-2215. c) Jin, L.; Tolentino, D. R.; Melaimi, M.; Bertrand, G. Isolation of Bis(copper) Key Intermediates in Cu-catalyzed Azide-Alkyne “Click Reaction" Sci. Adv. 2015, 1, e1500304.

[12] To our knowledge only 5 papers describe these compounds : a) Finnegan, W. G.; Henry, R. A.; Smith, G. B. L. 1-(Alkylamino)-guanidines. J. Am. Chem. Soc. 1952, 74, 2981-2983. b) Finnegan, W. G.; Henry, R. A. Synthesis and Reactions of 1-Nitroso-1-alkyl-2-guanyl-and -2carbamylhydrazines. J. Org. Chem. 1965, 30, 567-575. c) Masuda, K.; Kamiya, T.; Kashiwa, K. Studies on Mesoionic Compounds. III. Synthesis of $\Psi$-3-Aryl-5-imino-3, 5-dihydro-1-oxa-2, 3, 4triazole Hydrochlorides and Their Derivatives. Chem. Pharm. Bull. 1971, 19, 559-563. d) Jazwinski, J.; Staszewska-Krajewska, O. Synthesis and Multinuclear NMR Investigation of some Mesoionic 3-phenyl-5-imino-1,2,3,4-oxatriazole Imines. J. Mol. Struct. 2004, 687, 23-33. e) Cai, T. B.; Lu, D.; Tang, X.; Zhang, Y.; Landerholm, M.; Wang, P. G. New Glycosidase Activated Nitric Oxide Donors: Glycose and 3-Morphorlinosydnonimine Conjugates. J. Org. Chem. 2005, $70,3518-3524$. 


\section{Graphical Abstract}

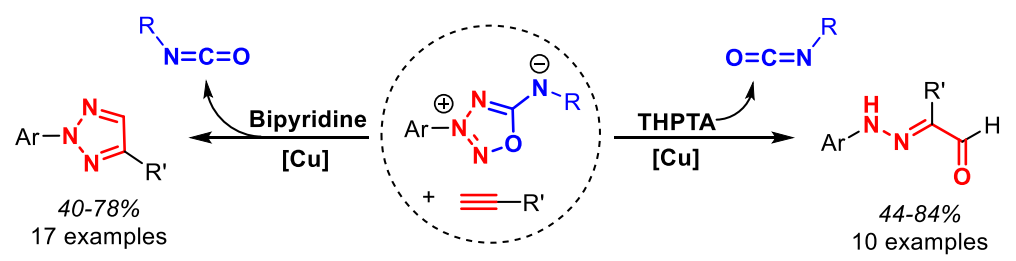

